\title{
Catalpol inhibits the proliferation, migration and metastasis of HCC cells by regulating miR-140-5p expression
}

\author{
LINSHENG WU ${ }^{1}$, HAOXIA $\mathrm{LI}^{1}$, SHENGYOU $\mathrm{CHEN}^{1}$, XIAOQIANG WU ${ }^{1}$, \\ ${\mathrm{XIAOMIN} \mathrm{CHEN}^{1} \text { and FANGPING WANG }}^{2}$ \\ ${ }^{1}$ Department of Geriatric Medicine, The Affiliated Hospital of Hangzhou Normal University, Hangzhou, Zhejiang 310000;
${ }^{2}$ Department of Hepatobiliary Surgery, The People's Hospital of Xinchang, Shaoxing, Zhejiang 312500, P.R. China
}

Received December 20, 2019; Accepted July 15, 2020

DOI: $10.3892 / \mathrm{mmr} .2020 .11667$

\begin{abstract}
Hepatocellular carcinoma (HCC) is a frequent malignant tumor. Catalpol is a Chinese medicine extract with a number of pharmacologically active properties. The present study aimed to investigate the effects and mechanisms of catalpol in HCC. HCC cells were treated with catalpol in the presence or absence of microRNA (miR)-140-5p inhibitor, and assays to determine cell viability, proliferation, invasion and migration were performed. Reverse transcription-quantitative PCR and western blotting were performed to determine the mRNA and protein expression levels of miR-140-5p, vimentin, $\mathrm{N}$-Cadherin and E-Cadherin. Moreover, cells were treated with catalpol in the absence or presence of transforming growth factor (TGF)- $\beta 1$, and the cell morphology was observed under a microscope. The results demonstrated that catalpol inhibited cell proliferation, invasion and migration, and decreased the expression levels of vimentin and $\mathrm{N}$-cadherin, but increased the expression levels of E-cadherin and miR-140-5p. Catalpol inhibited morphological changes in epithelial-mesenchymal transformation (EMT) of cells induced by TGF- $\beta 1$. Following inhibition of miR-140-5p expression, the proliferation, invasion and migration of HCC cells were promoted, E-cadherin expression was decreased, and the levels of vimentin and $\mathrm{N}$-cadherin were increased. The miR-140-5p inhibitor effectively reversed the inhibitory effect of catalpol on cell proliferation, invasion and migration. Thus, the results suggested that the antitumor potential of catalpol in HCC may be exerted by regulating the
\end{abstract}

Correspondence to: Dr Fangping Wang, Department of Hepatobiliary Surgery, The People's Hospital of Xinchang, 117 Middle Gushan Road, Nanming, Shaoxing, Zhejiang 312500, P.R. China

E-mail: fangp_wangfpi@163.com

Abbreviations: HCC, hepatocellular carcinoma; CCK-8, Cell Counting Kit-8; RT-qPCR, reverse transcription-quantitative PCR

Key words: catalpol, HCC, epithelial-mesenchymal transformation, microRNA-140-5p, proliferation expression of miR-140-5p to inhibit proliferation, invasion, migration and EMT of HCC cells.

\section{Introduction}

Hepatocellular carcinoma (HCC) is a frequent malignant tumor (1), according to the latest data from the American Cancer Society, there were 42,030 new cases of liver and intrahepatic bile duct cancer in 2019 (2). Since the early symptoms of HCC are not obvious, as they are small nodular hypercellular lesions (3), a notable proportion of patients are diagnosed with advanced $\mathrm{HCC}$, and few can be treated via radical resection (1), with $<30 \%$ of patients benefiting from curative treatment (4). Previous studies have reported that while surgical treatment is effective for patients with early $\mathrm{HCC}$, the prognosis of patients with intermediate and advanced stage HCC is poor due to the high frequency of metastasis and recurrence (4), and because surgery, chemotherapy, radiotherapy and other therapeutic methods are not effective and can possess toxic side effects (5-7). HCC caused $>0.6$ million deaths annually with the highest rates of death in Eastern and Southeast Asia (8). In the United States, the death rates from liver cancer increased by $43 \%$ (from 7.2 to 10.3 deaths per 100,000) between 2000 and 2016 (9). These challenges require novel potential biomarkers and targets to design more powerful treatments.

It has previously been reported that natural products from plants serve key roles in cancer treatment (10). Radix rehmanniae, a dry root of Rehmannia glutinosa Libosch, exhibits a number of pharmacological effects (11), including anti-inflammatory and antioxidative activities, and they can reduce blood glucose levels and partially recover nerve damage $(12,13)$. Catalpol is an iridoid glucoside compound isolated from the root of Radix rehmanniae that has active pharmacological functions, such as anti-cerebral ischemia injury, anti-aging, anti-inflammation and antitumor activity (14-16). Catalpol also produces cardiovascular protection via the PI3K/AKT signaling pathway in an ischemia/reperfusion rat model (17). The anti-aging effects of catalpol are achieved via promoting endogenous antioxidant enzyme activities, and restoring and improving metabolism failure (18). The antitumor potential of catalpol has been confirmed in numerous types of malignant tumors, including colon, breast and gastric cancer, as well as 
osteosarcoma, and a number of molecular mechanisms underlying this antitumor effect have been proposed (19-21). For example, catalpol suppresses proliferation, growth and invasion of CT26 colon cancer via inhibiting inflammation and tumor angiogenesis (19). Additionally, catalpol inhibits migration and induces apoptosis of gastric cancer cells in athymic nude mice (21). However, to the best of our knowledge, the anticancer effects of catalpol on HCC are rarely reported.

It has been revealed that microRNAs (miRNA/miR) are involved in tumor occurrence and progression $(22,23)$. miR-140-5p is a tumor inhibitor that significantly blocks migration, invasion and other biological features of tumor cells (24-26). Moreover, miR-140-5p has been shown to notably inhibit cell proliferation, migration and invasion in HCC $(27,28)$. Catalpol can reduce the proliferation of cancer cells via regulating miRNAs. For example, catalpol suppresses proliferation and promotes apoptosis of MCF-7 breast cancer cells via increasing the expression of miR-146a (20). Catalpol attenuates cardiomyocyte apoptosis in diabetic cardiomyopathy via the nuclear paraspeckle assembly transcript 1 (Neat1)/miR-140-5p/histone deacetylase 4 axis (29). However, to the best of our knowledge, whether catalpol is involved in HCC by regulating miR-140-5p has not been previously reported. The present study investigated the role and mechanism of catalpol in HCC cells in vitro.

\section{Materials and methods}

Cell culture. Human HCC cell lines HCCLM3 and Huh7 (both American Type Culture Collection) were cultured in DMEM (Sigma-Aldrich; Merck KGaA) supplemented with 10\% FBS (Sigma-Aldrich; Merck KGaA) in an incubator at $37^{\circ} \mathrm{C}$ with $5 \% \mathrm{CO}_{2}$.

Transfection. The 2-O-methyl type inhibitor for miR-140-5p (Shanghai GenePharma Co., Ltd.), inhibitor control (Shanghai GenePharma Co., Ltd.) and Lipofectamine ${ }^{\circledR} 2000$ transfection reagent (Invitrogen; Thermo Fisher Scientific, Inc.) were used in cell transfection. Lipofectamine $2000(1 \mu \mathrm{l})$ was diluted in $50 \mu \mathrm{l}$ Opti-MEM (Invitrogen; Thermo Fisher Scientific, Inc.), and $30 \mathrm{pmol}$ miR-140-5p inhibitor was diluted in $50 \mu \mathrm{l}$ Opti-MEM. Huh7 and HCCLM3 cells $\left(2 \times 10^{5}\right.$ cells/well) were inoculated into a 96-well culture plate, added with the diluted Lipofectamine 2000 and miR-140-5p inhibitor and incubated at $37^{\circ} \mathrm{C}$ with $5 \% \mathrm{CO}_{2}$ for $48 \mathrm{~h}$. Following this, cells were collected for subsequent experiments. The cells in the Control group were untreated, and those in the Inhibitor control group were treated with transfection agents only. The primer sequences are presented in Table I.

Drug and TGF- $\beta 1$ treatment. For catalpol (Sigma-Aldrich; Merck KGaA) treatment, HCCLM3 and Huh7 cells were adjusted to $1 \times 10^{4}$ cells/ml density using DMEM, seeded into 96-well plates and treated with different concentrations of catalpol $(0.0,2.5,5.0,10.0,20.0,50.0$ and $100.0 \mu \mathrm{M})$ for 24,48 and $72 \mathrm{~h}$ at $37^{\circ} \mathrm{C}$. HCCLM3 and Huh7 cells were collected for cell viability experiments.

In order to observe the effect of catalpol treatment on morphological changes of TGF- $\beta 1$-treated cancer cells, HCCLM3 and Huh7 cells were divided into Control (no treatment), TGF- $\beta 1$ [treated with $5 \mathrm{ng} / \mathrm{ml}$ TGF- $\beta 1$ (Miltenyi Biotec, Inc.) for $48 \mathrm{~h}$ at $37^{\circ} \mathrm{C}$ ] and Catalpol + TGF- $\beta 1$ (treated with $50 \mu \mathrm{M}$ catalpol and stimulated with $5 \mathrm{ng} / \mathrm{ml}$ TGF- $\beta 1$ for $48 \mathrm{~h}$ at $37^{\circ} \mathrm{C}$ ) groups.

Morphological observation. HCCLM3 and Huh7 cells $\left(1 \times 10^{4}\right.$ cells/well) were seeded onto 24 -well plates. The Control group consisted of untreated cells cultured in DMEM for $48 \mathrm{~h}$ at $37^{\circ} \mathrm{C}$; the TGF- $\beta 1$ group was treated with DMEM containing TGF- $\beta 1\left(5 \mathrm{ng} / \mathrm{ml}\right.$ for $48 \mathrm{~h}$ at $\left.37^{\circ} \mathrm{C}\right)$; and the Catalpol + TGF- $\beta 1$ group were treated with DMEM containing TGF- $\beta 1(5 \mathrm{ng} / \mathrm{ml})$ and catalpol $(50 \mu \mathrm{M})$ for $48 \mathrm{~h}$ at $37^{\circ} \mathrm{C}$. After $48 \mathrm{~h}$, cells were observed under a light microscope (magnification, x200; CKX41; Olympus Corporation).

Cell Counting Kit-8 (CCK-8) assay. A CCK-8 assay was performed to detect viability of HCCLM3 and Huh7 cells in vitro. Cells $\left(2 \times 10^{3}\right.$ cells/well $)$ were seeded onto 96 -well plates and cultured for 24,48 and $72 \mathrm{~h}$ at $37^{\circ} \mathrm{C}$ with $5 \% \mathrm{CO}_{2}$. Following the incubation, $10 \mu \mathrm{l} \mathrm{CCK}-8$ (Dojindo Molecular Technologies, Inc.) was added into each well, followed by a 2-h incubation at $37^{\circ} \mathrm{C}$, according to the manufacturer's instructions. The optical density at $450 \mathrm{~nm}$ was recorded using a microplate reader (Model 680; Bio-Rad Laboratories, Inc.).

5-Bromo-2-deoxyuridine (BrdU) assay. A BrdU assay was used to measure the proliferation of HCCLM3 and Huh7 cells in vitro. Cells were seeded onto 96 -well plates ( $1 \times 10^{4}$ cells/well), incubated for $48 \mathrm{~h}$ at $37^{\circ} \mathrm{C}$, and then incubated with BrdU $(20 \mathrm{mM})$ for $4 \mathrm{~h}$ at $37^{\circ} \mathrm{C}$. Cells were permeabilized with $0.1 \%$ Triton-100 for $10 \mathrm{~min}$ at room temperature, and blocked with $3 \%$ FBS at room temperature for $1 \mathrm{~h}$, and cellular DNA was denatured via 50 units DNase I for $30 \mathrm{~min}$ at $37^{\circ} \mathrm{C}$. The Alexa Fluor ${ }^{\circledR} 488$-conjugated anti-BrdU monoclonal antibody (1:200; cat. no. IC7225G; R\&D Systems, Inc.) was added to cells and incubated at $4^{\circ} \mathrm{C}$ overnight. The next day, nuclei were counterstained with DAPI for $10 \mathrm{~min}$ at room temperature, and images were captured under a fluorescence microscope (magnification, x200; SteREO Lumar.V12; Zeiss AG).

Wound healing assay. A wound healing assay was performed to detect the migration of HCCLM3 and Huh7 cells. The treated cells $\left(1 \times 10^{6}\right.$ cells/well) were plated on a 6 -well plate, and a straight wound was created using a sterile tip after cell confluence reached $>90 \%$. The cells were cultured in serum-free DMEM. Floating cells were removed using DMEM at 0 and $24 \mathrm{~h}$, and images were captured using a light microscope (magnification, x100; CKX41; Olympus Corporation) and analyzed via ImageJ software 1.8.0 (National Institutes of Health).

Transwell assay. A Transwell assay (Costar; Corning, Inc.) was used to determine the invasion ability of HCCLM3 and Huh7 cells. The Matrigel-precoated (at $37^{\circ} \mathrm{C}$ for $4 \mathrm{~h}$ ) upper chamber of the Transwell inserts ( $8 \mu \mathrm{m}$; Corning, Inc.) containing FBS-free DMEM was added with the treated cells $\left(2 \times 10^{4}\right.$ cells $\left./ \mathrm{ml}\right)$ and incubated for $24 \mathrm{~h}$ at $37^{\circ} \mathrm{C}$ with $5 \% \mathrm{CO}_{2}$, while DMEM supplemented with $10 \%$ FBS was added into the lower chamber. The remaining cells in the upper chamber were removed using a cotton swab, while those in the lower 
Table I. Sequences used for transfection.

\begin{tabular}{lc}
\hline Name & Primer $\left(5^{\prime} \rightarrow 3^{\prime}\right)$ \\
\hline $\begin{array}{l}\text { MicroRNA-140-5p } \\
\text { inhibitor }\end{array}$ & CUACCAUAGGGUAAAACCACUG \\
Inhibitor & UCUACUCUUUCUAGGAGGUUGUGA \\
control & \\
\hline
\end{tabular}

chamber surface were treated with $4 \%$ paraformaldehyde for $15 \mathrm{~min}$ at room temperature and stained with $0.1 \%$ gentian violet for $30 \mathrm{~min}$ at room temperature. Images were captured using a light microscope (magnification, x200; Digital Microscope VHX-5000; Keyence Corporation).

Bioinformatics analysis. The target gene of miR-140-5p was detected via computational analysis performed using TargetScan software (version 7.2; targetscan.org/vert_72), as previously described (30).

Reverse transcription-quantitative $(R T-q) P C R$. RNA was extracted from cells using TRIzol ${ }^{\circledR}$ reagent (Invitrogen; Thermo Fisher Scientific, Inc.), and purity and concentration were assessed via NanoDrop 2000/2000c (Thermo Fisher Scientific, Inc.). To detect miR-140-5p expression levels, TaqMan $^{\mathrm{TM}}$ MicroRNA Reverse Transcription kit (Applied Biosystems; Thermo Fisher Scientific, Inc.) was used for reverse transcription of RNA into cDNA, at $42^{\circ} \mathrm{C}$ for $30 \mathrm{~min}$ and $85^{\circ} \mathrm{C}$ for 5 min. qPCR was performed using a Hairpin-it ${ }^{\mathrm{TM}}$ miRNA qPCR Quantitation kit (Shanghai GenePharma Co., Ltd.) and 7500 Fast Real-Time PCR System (Applied Biosystems; Thermo Fisher Scientific, Inc.) under the following conditions: Initial denaturation at $95^{\circ} \mathrm{C}$ for $3 \mathrm{~min}$, followed by 40 cycles at $95^{\circ} \mathrm{C}$ for $12 \mathrm{sec}$, and $62^{\circ} \mathrm{C}$ for $40 \mathrm{sec}$.

For the detection of mRNA expression levels, RNA ( $2 \mathrm{mg}$ ) was reverse-transcribed into cDNA using a TaqMan RT kit (Applied Biosystems; Thermo Fisher Scientific, Inc.), at $37^{\circ} \mathrm{C}$ for $30 \mathrm{~min}$ and $85^{\circ} \mathrm{C}$ for $5 \mathrm{~min}$. RT-qPCR was performed using an ABI 7500 Real-Time PCR system (Applied Biosystems; Thermo Fisher Scientific, Inc.) and SYBR-Green PCR Master Mix kit (Takara Bio, Inc.) at $94^{\circ} \mathrm{C}$ for $2 \mathrm{~min}$, followed by 40 cycles at $94^{\circ} \mathrm{C}$ for $20 \mathrm{sec}, 58^{\circ} \mathrm{C}$ for $20 \mathrm{sec}$ and $72^{\circ} \mathrm{C}$ for $20 \mathrm{sec}$. The relative mRNA expression levels were calculated via the $2^{-\Delta \Delta \mathrm{Cq}}$ (31) method. U6 and GAPDH were used as endogenous controls. Primers are presented in Table II.

Western blotting. Proteins were lysed using RIPA buffer (Beyotime Institute of Biotechnology), and the concentration was determined via Bio-Rad DC Assay kit (Bio-Rad Laboratories, Inc.). The protein samples (20 $\mu \mathrm{g} / \mathrm{lane})$ were separated on 10\% SDS-PAGE (Invitrogen; Thermo Fisher Scientific, Inc.), and transferred onto PVDF membranes (EMD Millipore), which were blocked with 5\% non-fat dry milk for $2 \mathrm{~h}$ at room temperature. The membranes were then incubated with vimentin (1:1,000; cat. no. ab92547; Abcam), N-cadherin (1:1,000; cat. no. ab18203; Abcam), E-cadherin (1:10,000; cat. no. ab40772; Abcam) and GAPDH (1:2,000; cat. no. ab8245; Abcam) at $4^{\circ} \mathrm{C}$ overnight, and subsequently incubated with horseradish peroxidase (HRP)-conjugated goat anti-mouse IgG H\&L (1:2,000; cat. no. ab205719; Abcam) and HRP-conjugated goat anti-rabbit IgG H\&L (1:2,000; cat. no. ab205718; Abcam) for $1 \mathrm{~h}$ at room temperature. Bands of specific proteins were analyzed via SuperECL Plus detection reagent (Nanjing KeyGEN Biotech Co., Ltd.) and quantified using ImageJ Software (version 1.46; National Institutes of Health). GAPDH was used as an internal control.

Statistical analysis. The data were analyzed and plotted using SPSS software (version 20.0; IBM Corp.) and presented as the mean \pm SD of three independent repeats. Differences between groups were analyzed using unpaired Student's t-test or one-way ANOVA followed by Tukey's post hoc test. $\mathrm{P}<0.05$ was considered to indicate a statistically significant difference.

\section{Results}

Catalpol suppresses the viability of HCC cells. In order to investigate the role of catalpol in HCC cells, Huh7 and HCCLM3 cells were treated with different concentrations of catalpol $(0.0,2.5,5.0,10.0,20.0,50.0$ and $100.0 \mu \mathrm{M})$ to determine the optimal drug concentration for subsequent experiments. CCK-8 results demonstrated that viability of Huh7 (Fig. 1A) and HCCLM3 (Fig. 1B) cells was decreased by different concentrations of catalpol at three time points in a dose-dependent manner compared with untreated cells $(\mathrm{P}<0.05)$. Notably, the cell viability was decreased by $>50 \%$ following treatment with $50 \mu \mathrm{M}$ catalpol for $48 \mathrm{~h}$. Thus, treatment with $50 \mu \mathrm{M}$ catalpol for $48 \mathrm{~h}$ was selected for use in further in vitro functional measurements.

Catalpol inhibits proliferation, invasion and migration of $H C C$ cells, and increases miR-140-5p expression. After treating HCC cells with $50 \mu \mathrm{M}$ catalpol for $48 \mathrm{~h}$, RT-qPCR results demonstrated that miR-140-5p expression levels in Huh7 (Fig. 2A) and HCCLM3 (Fig. 2B) cells were increased compared with those in the Control group $(\mathrm{P}<0.001)$.

BrdU assay results suggested that $50 \mu \mathrm{M}$ catalpol treatment for $48 \mathrm{~h}$ decreased the proportion of BrdU-positive cells compared with the Control group in Huh7 ( $\mathrm{P}<0.01$; Fig. 2C) and HCCLM3 cells $(\mathrm{P}<0.001$; Fig. 2D). The occurrence of EMT in tumor cells requires the induction of signaling factors, such as TGF- $\beta 1$, that promote $\mathrm{N}$-cadherin expression but inhibit E-cadherin expression (32). TGF- $\beta 1$ was used to treat Huh7 and HCCLM3 (Fig. 2E) cells, and it was observed that, compared with the Control group, the morphology of Huh7 and HCCLM3 cells in the TGF- $\beta 1$ group was altered, indicated by a spindle shape and decreased intercellular connections. Compared with TGF- $\beta 1$-treated cells, the number of spindle cells in the Catalpol + TGF- $\beta 1$ group was decreased, cell morphology recovered and intercellular connections were tight.

The effects of catalpol $(50 \mu \mathrm{M})$ on the migration and invasion of Huh7 and HCCLM3 cells were determined via wound healing and Transwell assays. Following catalpol treatment, Huh7 and HCCLM3 cells exhibited decreased migration and invasion compared with those in the Control group $(\mathrm{P}<0.01$ or $\mathrm{P}<0.001$; Fig. 3). Consistent with these results, RT-qPCR and western blotting identified that catalpol 
Table II. Primers used for reverse transcription-quantitative PCR.

\begin{tabular}{lll}
\hline Name & \multicolumn{1}{c}{ Forward $\left(5^{\prime} \rightarrow 3^{\prime}\right)$} & \multicolumn{1}{c}{ Reverse $\left(5^{\prime} \rightarrow 3^{\prime}\right)$} \\
\hline MicroRNA-140-5p & GAGTGTCAGTGGTTTTACCCT & GCAGGGTCCGAGGTATTC \\
U6 & CGCTTCGGCACATATACTA & CGCTTCACGAATTTGCGTGTCA \\
Vimentin & AGAGAACTTTGCCGTTGAAGC & ACGAAGGTGACGAGCCATT \\
N-cadherin & GACGGTTCGCCATCCAGAC & TCGATTGGTTTGACCACGG \\
E-cadherin & TTGCTACTGGAACAGGGACA & GTATTGGGAGGAAGGTCTGC \\
GAPDH & AACTTTGGCATTGTGGAAGG & ACACATTGGGGGTAGGAACA
\end{tabular}

decreased expression levels of vimentin and $\mathrm{N}$-cadherin in Huh7 cells (Fig. 4A and B), whereas the expression of E-cadherin was increased compared with the Control group $(\mathrm{P}<0.001)$. Moreover, vimentin and $\mathrm{N}$-cadherin in HCCLM3 cells (Fig. 4C and D) had low expression levels and E-cadherin was highly expressed in the Catalpol group compared with the Control group $(\mathrm{P}<0.001)$. Therefore, it was suggested that catalpol $(50 \mu \mathrm{M})$ induced inhibitory effects on cell proliferation, invasion and migration, as well as EMT, but increased miR-140-5p expression.

Catalpol mediates biological function of HCC cells via regulating $m i R-140-5 p$ expression. It was demonstrated that $50 \mu \mathrm{M}$ catalpol increased miR-140-5p expression in Huh7 and HCCLM3 cells. Therefore, a miR-140-5p inhibitor was transfected into $\mathrm{HHC}$ cells to investigate whether catalpol inhibits HCC cell proliferation and metastasis via regulating miR-140-5p expression. Huh7 and HCCLM3 cells were transfected with miR-140-5p inhibitor and treated with $50 \mu \mathrm{M}$ catalpol for $48 \mathrm{~h}$. RT-qPCR results indicated that, compared with the Inhibitor control group, miR-140-5p expression levels in Huh7 (Fig. 5A) and HCCLM3 (Fig. 5B) cells were decreased by miR-140-5p inhibitor $(\mathrm{P}<0.01)$.

Following transfection with miR-140-5p inhibitor and treatment with $50 \mu \mathrm{M}$ catalpol for $48 \mathrm{~h}$, the CCK- 8 results suggested that the viability of Huh7 (Fig. 5C) and HCCLM3 (Fig. 5D) cells transfected with miR-140-5p inhibitor control and treated with catalpol was lower compared with those transfected with miR-140-5p inhibitor control only $(\mathrm{P}<0.01)$. Moreover, the viability of cells treated with Catalpol + Inhibitor was higher compared with those treated with Catalpol + Inhibitor control $(\mathrm{P}<0.001)$, but lower compared with the cells transfected with miR-140-5p inhibitor alone $(\mathrm{P}<0.05)$.

Wound healing and Transwell assays were performed to determine cell migration and invasion. Compared with the Inhibitor control group, migration of Huh7 (Fig. 6A and B) and HCCLM3 cells (Fig. 6C and D) in the Catalpol + Inhibitor control group was decreased $(\mathrm{P}<0.001)$, but increased in the Inhibitor group $(\mathrm{P}<0.001)$. Cell migration was higher in the Catalpol + Inhibitor group compared with the Catalpol + Inhibitor control group, but lower compared with the Inhibitor group (Fig. 6A-D; $\mathrm{P}<0.001$ ). Furthermore, the invasion of Huh7 (Fig. 6E and F) and HCCLM3 (Fig. 6G and H) cells in the Catalpol + Inhibitor control group was decreased $(\mathrm{P}<0.001)$, but increased in Inhibitor group compared with Inhibitor control group $(\mathrm{P}<0.05)$. The invasive ability of cells transfected with miR-140-5p inhibitor and treated with Catalpol
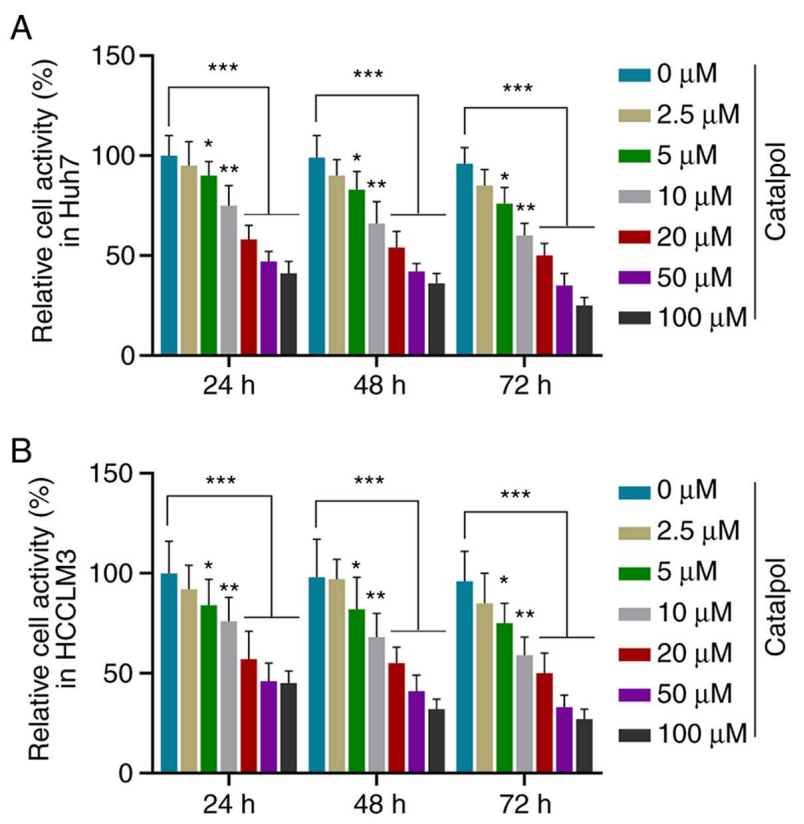

Figure 1. Effects of catalpol on viability of hepatocellular carcinoma cell lines. (A) Huh7 and (B) HCCLM3 cells were treated with different concentrations of catalpol $(0.0,2.5,5.0,10.0,20.0,50.0$ and $100.0 \mu \mathrm{M})$, and a Cell Counting Kit- 8 assay was performed. ${ }^{*} \mathrm{P}<0.05,{ }^{* *} \mathrm{P}<0.01,{ }^{* * *} \mathrm{P}<0.001$ vs. $0 \mu \mathrm{M}$.

was higher compared with the Catalpol + Inhibitor control group, but lower compared with the Inhibitor group $(\mathrm{P}<0.001)$. Thus, catalpol treatment inhibited the viability, invasion and migration of Huh7 and HCCLM3 cells, while the miR-140-5p inhibitor significantly reversed the effects of catalpol on cells.

Catalpol mediates EMT of HCC cells via regulating miR-140-5p expression. EMT is a biological process in which the epithelial phenotype is transformed into a mesenchymal phenotype; during EMT, the expression of E-cadherin is decreased, and those of vimentin and $\mathrm{N}$-cadherin are increased $(33,34)$. In order to determine whether miR-140-5p targets vimentin, $\mathrm{N}$-cadherin or E-cadherin, bioinformatics was conducted to predict miR-140-5p target genes, and it was identified that there was no binding site between them. Thus, miR-140-5p did not target vimentin, N-cadherin and E-cadherin.

RT-qPCR and western blotting results demonstrated that for Huh7 cells, transfection with inhibitor control and treatment with catalpol decreased the expression levels of vimentin and $\mathrm{N}$-cadherin, and increased those of 
A

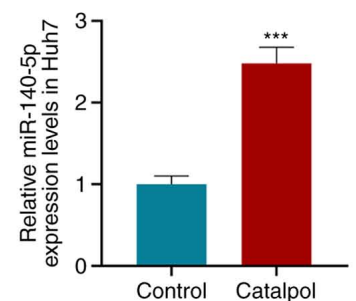

C
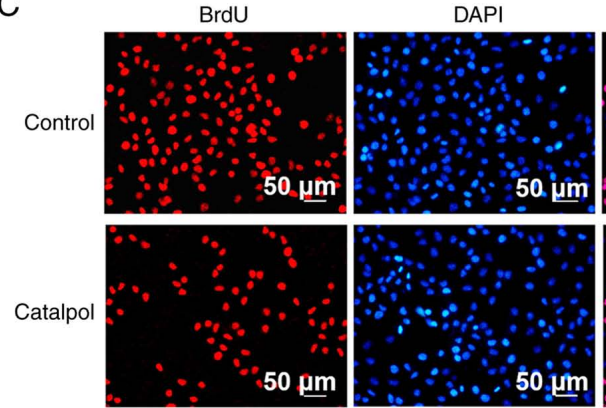

B

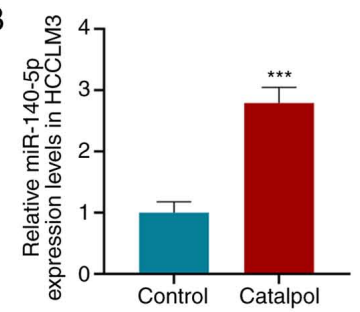

Merge
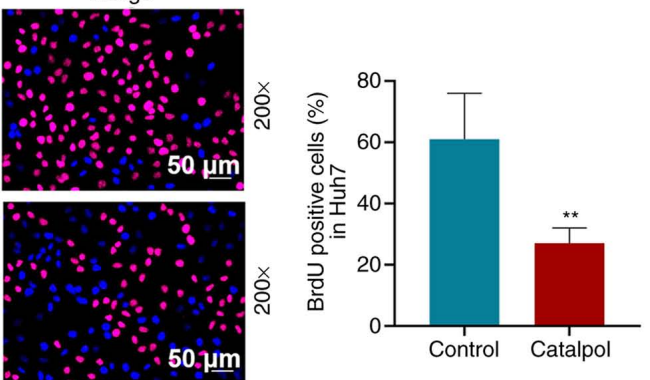

DAPI

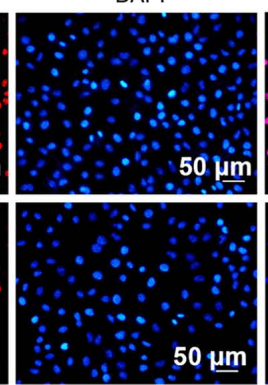

Merge

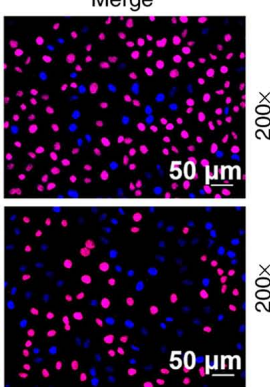

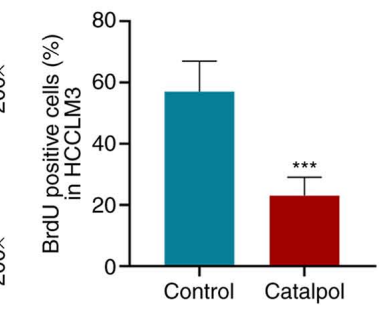

E

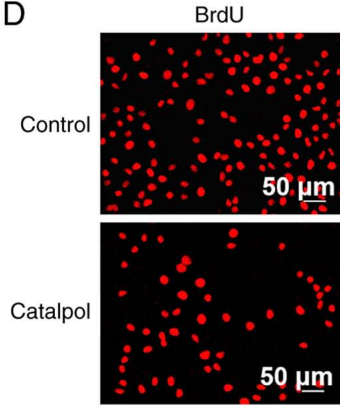

Control

TGF- $\beta 1$ Catalpol+TGF- $\beta 1$
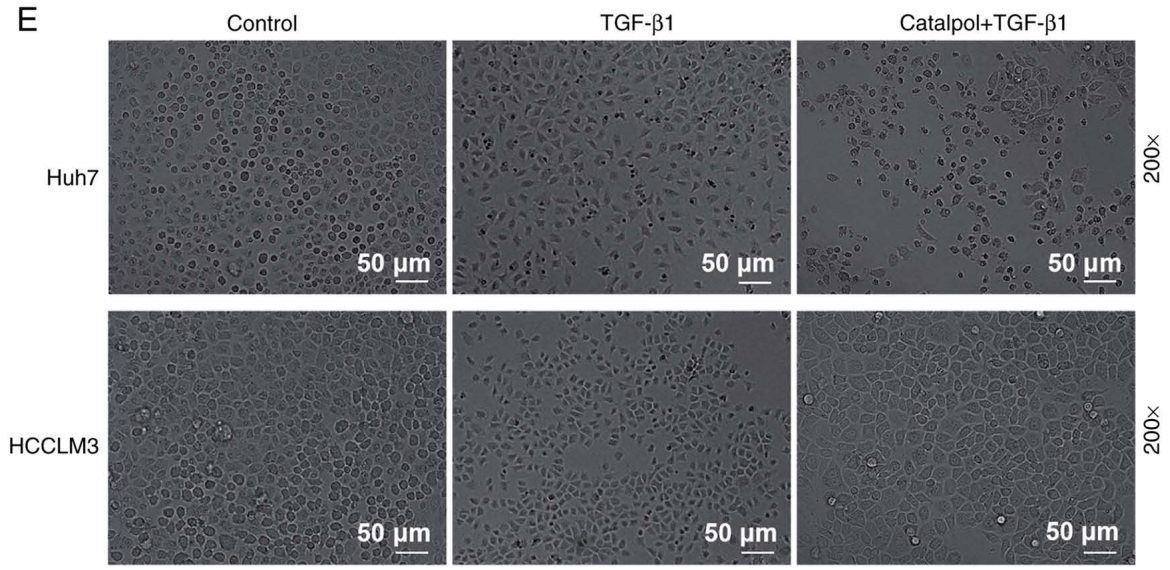

Figure 2. Effects of catalpol on cell proliferation and metastasis, and miR-140-5p expression in cells treated with catalpol (50 $\mu \mathrm{M})$ for $48 \mathrm{~h}$. mRNA expression levels of miR-140-5p in (A) Huh7 and (B) HCCLM3 cells were determined via reverse transcription-quantitative PCR. Proliferation of (C) Huh7 and (D) HCCLM3 cells was determined via a BrdU assay. (E) HCCLM3 and Huh7 cells were treated with TGF- $\beta 1$ or catalpol, and morphological changes of cells were observed under an inverted microscope. ${ }^{* *} \mathrm{P}<0.01,{ }^{* * *} \mathrm{P}<0.001$ vs. Control. BrdU, 5 -bromo-2-deoxyuridine; miR, microRNA; TGF- $\beta 1$, transforming growth factor- $\beta 1$.

E-cadherin, compared with the Inhibitor control group $(\mathrm{P}<0.001$; Fig. 7A and $\mathrm{B})$. However, compared with the Inhibitor control group, expression levels of vimentin and $\mathrm{N}$-cadherin in the Inhibitor group were higher, and those of E-cadherin were lower $(\mathrm{P}<0.001)$. The expression levels of vimentin and $\mathrm{N}$-cadherin in the Catalpol + Inhibitor group were higher compared with those in the Catalpol + Inhibitor control group but lower compared with those in the Inhibitor group $(\mathrm{P}<0.001)$. Furthermore, E-cadherin expression levels were lower compared with those in the Catalpol + Inhibitor control group but higher compared with the Inhibitor group $(\mathrm{P}<0.001)$.

Similar effects on the expression levels of vimentin, N-cadherin and E-cadherin of HCCLM3 cells were observed $(\mathrm{P}<0.05$; Fig. 7C and D). Catalpol significantly inhibited vimentin and $\mathrm{N}$-cadherin expression levels, but increased E-cadherin expression in Huh7 and HCCLM3 cells, while the miR-140-5p inhibitor produced the opposite effects and reversed the effects of catalpol on vimentin, $\mathrm{N}$-cadherin and E-cadherin expression levels. These results indicated that the miR-140-5p inhibitor promoted EMT in 
A
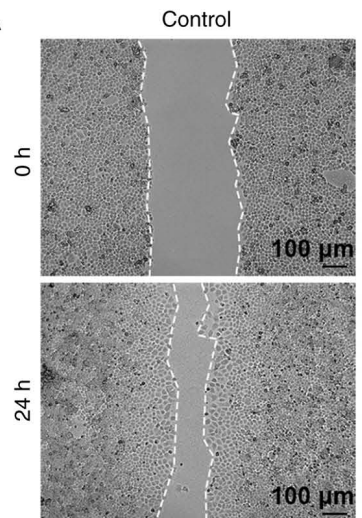

B
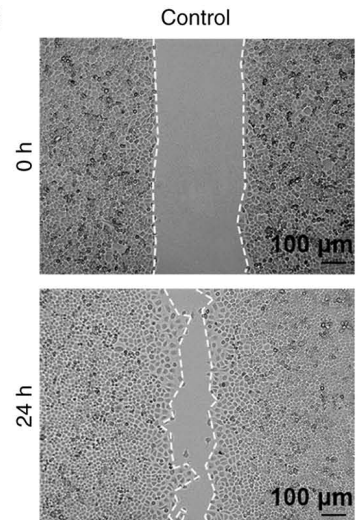

$100 \mu \mathrm{m}$

C
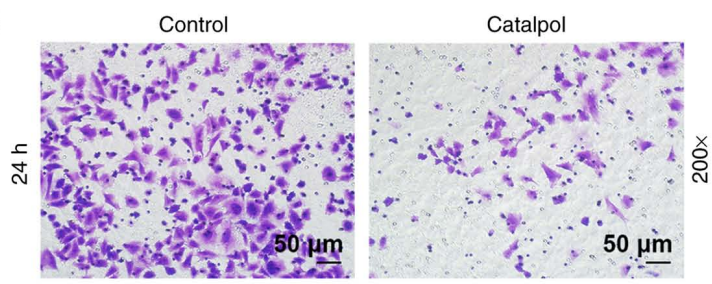

D

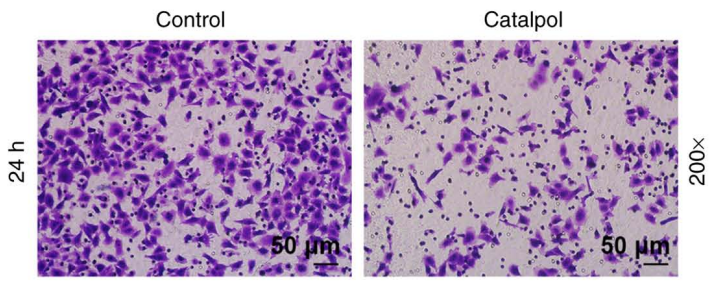

Catalpol
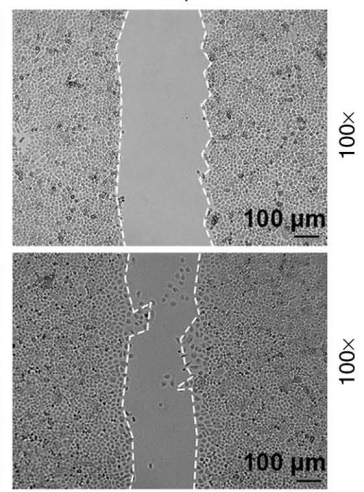

Catalpol

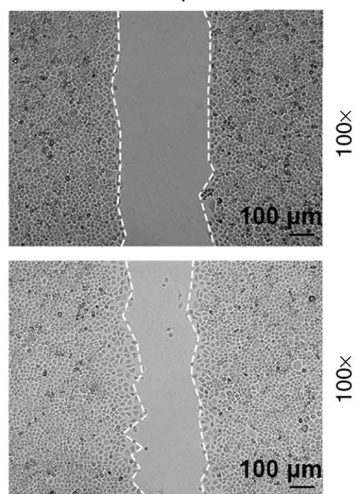

훙
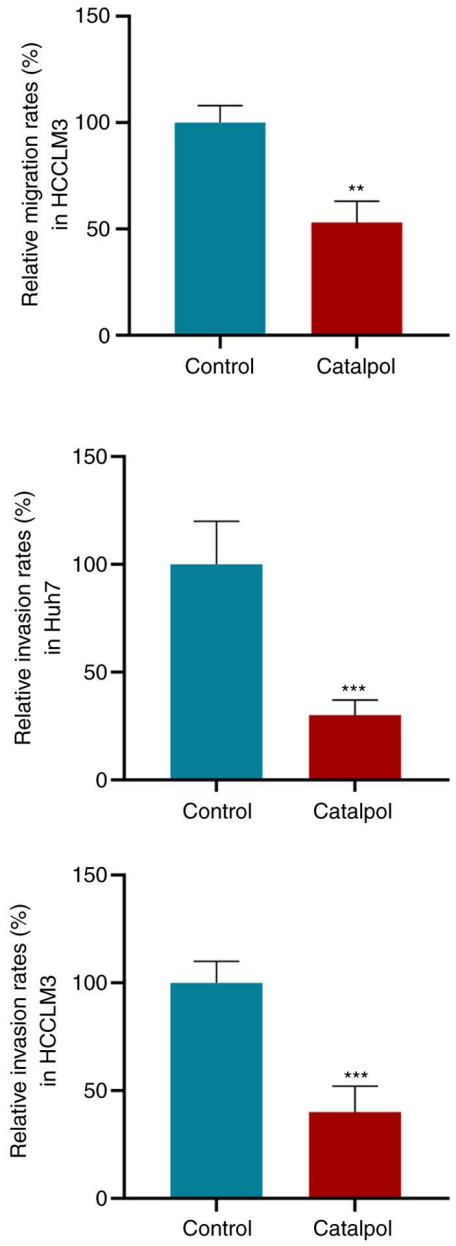

Figure 3. Effects of catalpol on migration and invasion of cells treated with catalpol (50 $\mu \mathrm{M})$ for 48 h. Migration of (A) Huh7 and (B) HCCLM3 cells was determined via a wound healing assay. Invasion of (C) Huh7 and (D) HCCLM3 cells was determined via a Transwell assay. ${ }^{* *} \mathrm{P}<0.01,{ }^{* * *} \mathrm{P}<0.001$ vs. Control.

Huh7 and HCCLM3 cells, and catalpol reversed the promoting effect of miR-140-5p inhibitor on EMT.

\section{Discussion}

$\mathrm{HCC}$ is the fourth most common cause of cancer-related deaths worldwide (35), with a 5-year survival rate of $18 \%$ (36), and thus, there is a need to identify effective clinical treatment methods $(37,38)$. Catalpol exhibits pharmacological effects in a number of diseases, such as ischemia/reperfusion (17) and diabetes (39), via regulating the NF- $\mathrm{B}, \mathrm{PI} 3 \mathrm{~K} / \mathrm{AKT}$ and brain-derived neurotrophic factor pathways (17,40-43). The present study performed in vitro functional experiments, and demonstrated that catalpol treatment significantly increased the expression of miR-140-5p, and effectively inhibited EMT of HCC cells, as well as cell migration and invasion.

$\mathrm{HCC}$ is characterized by insidious onset, rapid progression, strong invasion and metastasis (44). Malignant tumors 

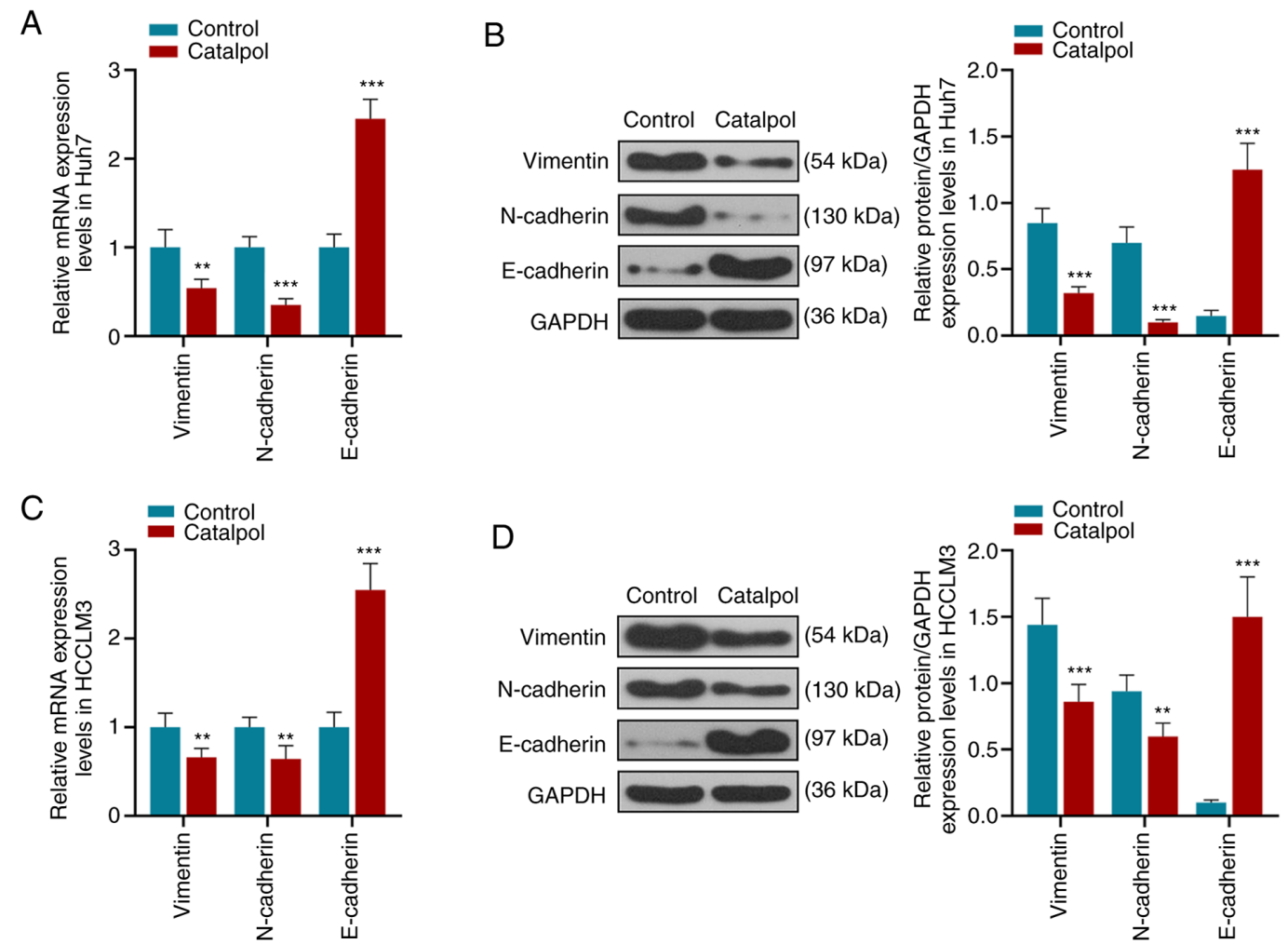

Figure 4. Effects of catalpol on epithelial-mesenchymal transformation of hepatocellular carcinoma cell lines. (A) mRNA and (B) protein expression levels of vimentin, N-cadherin and E-cadherin in Huh7 cells were determined via RT-qPCR and western blotting. (C) mRNA and (D) protein expression levels of vimentin, $\mathrm{N}$-cadherin and E-cadherin in HCCLM3 cells were determined via RT-qPCR and western blotting. ${ }^{* *} \mathrm{P}<0.01,{ }^{* * * *} \mathrm{P}<0.001$ vs. Control. RT-qPCR, reverse transcription-quantitative PCR.

A

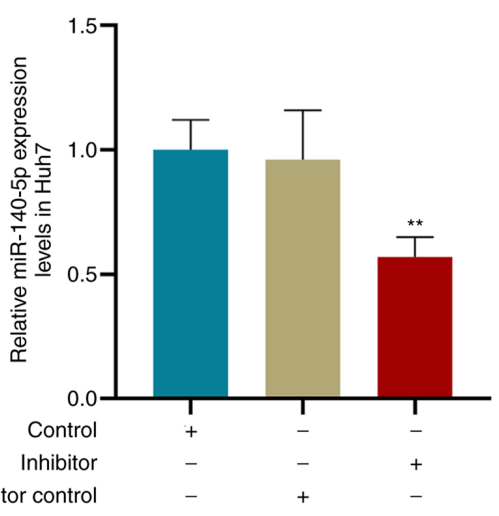

C

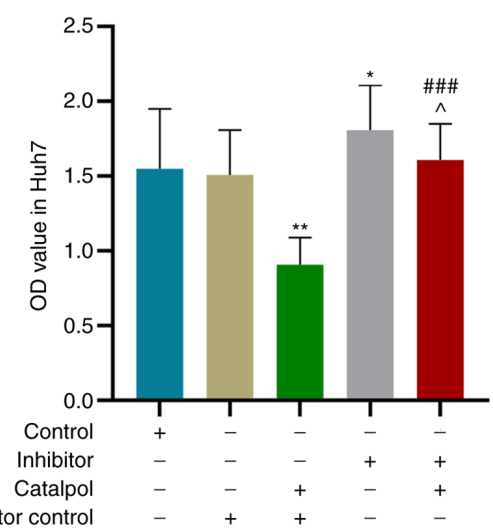

B
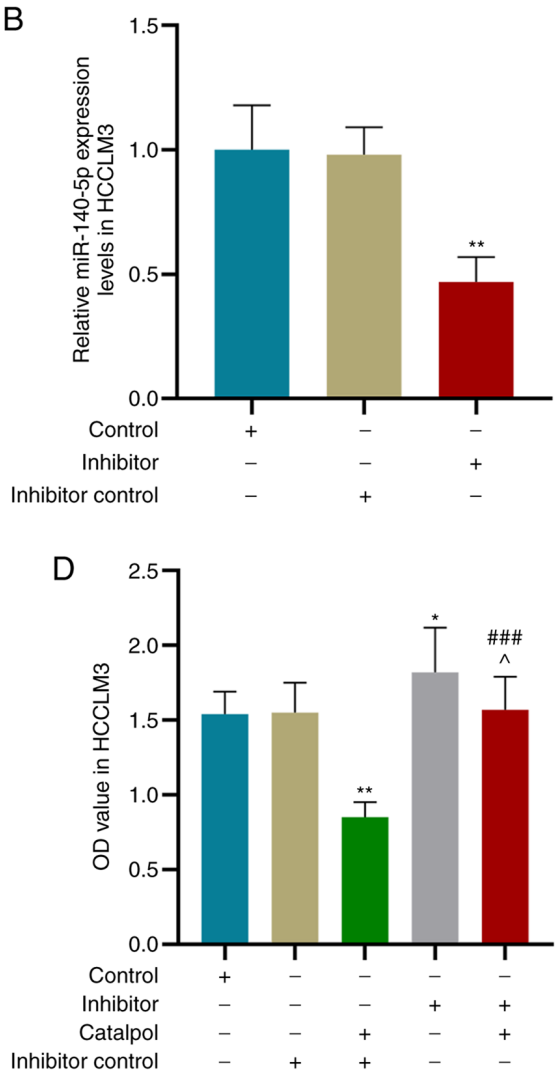

Figure 5. Catalpol inhibits proliferation of hepatocellular carcinoma cells via increasing miR-140-5p. (A) Huh7 and (B) HCCLM3 cells were transfected with miR-140-5p inhibitor, and reverse transcription-quantitative PCR was performed. (C) Huh7 and (D) HCCLM3 cells were treated with miR-140-5p inhibitor and/or catalpol $(50 \mu \mathrm{M})$ for $48 \mathrm{~h}$, and cell viability was detected via Cell Counting Kit-8 assay. ${ }^{*} \mathrm{P}<0.05,{ }^{* *} \mathrm{P}<0.01$ vs. Inhibitor control; ${ }^{* \# \#} \mathrm{P}<0.001$ vs. Catalpo $1+$ Inhibitor control; ${ }^{\wedge} \mathrm{P}<0.05$ vs. Inhibitor. miR, microRNA; OD, optical density. 


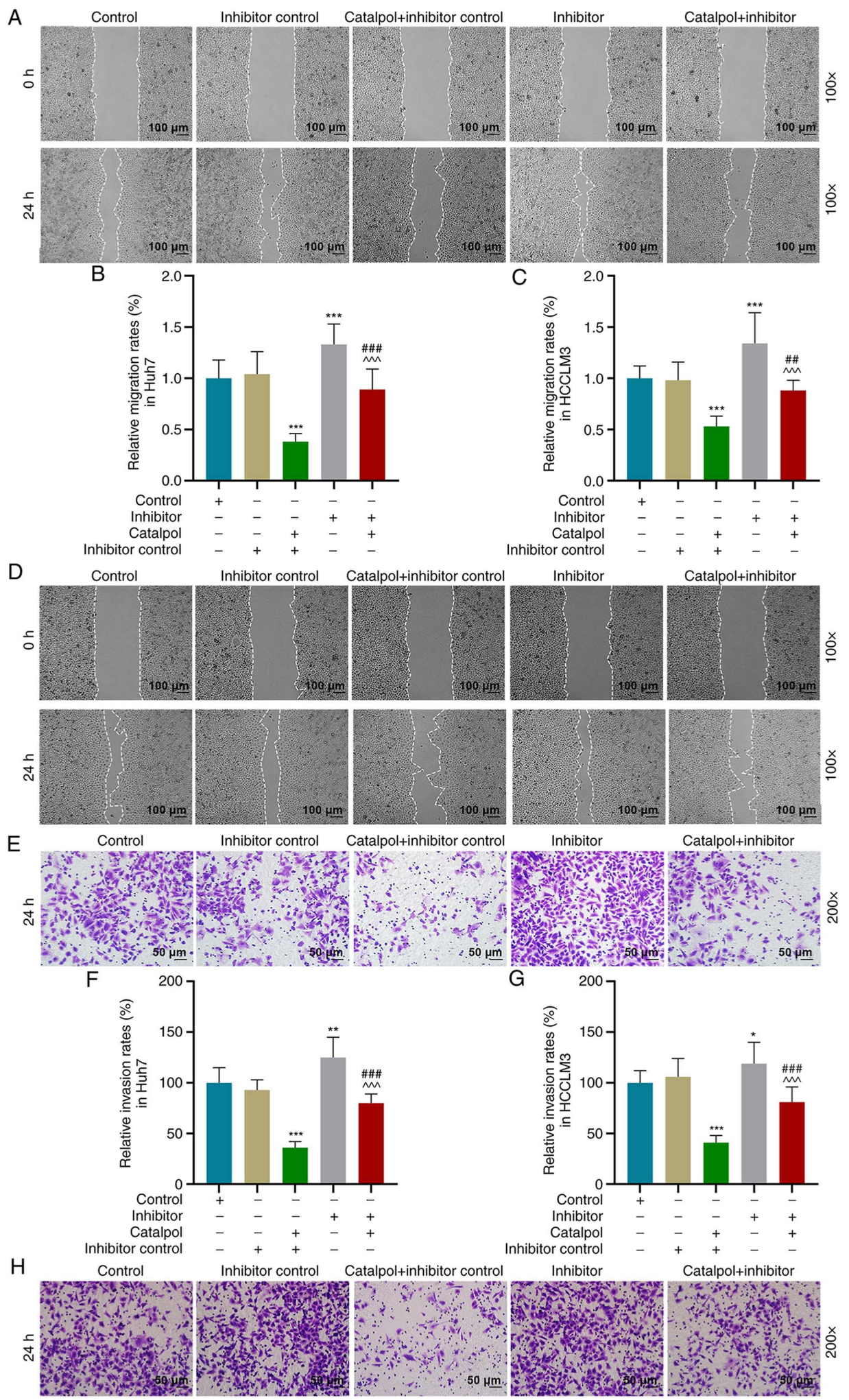

Figure 6. Catalpol inhibits migration and invasion of hepatocellular carcinoma cells via upregulating miR-140-5p. (A) Migration of Huh7 cells was determined via wound healing assay. (B) Relative migration of Huh7 cells in each group. (C) Migration of HCCLM3 cells in each group, which was (D) determined via a wound healing assay. (E) Invasion of Huh7 cells was determined via Transwell assay. Relative invasion of (F) Huh7 and (G) HCCLM3 cells in each group. (H) Invasion of HCCLM3 cells was determined via Transwell assay. ${ }^{*} \mathrm{P}<0.05,{ }^{* *} \mathrm{P}<0.01,{ }^{* * * *} \mathrm{P}<0.001$ vs. Inhibitor control; ${ }^{\# \#} \mathrm{P}<0.01$, ${ }^{\# \# \#} \mathrm{P}<0.001$ vs. Catalpol + In hibitor control; ${ }^{\wedge \wedge} \mathrm{P}<0.001$ vs. Inhibitor.

are characterized by uncontrolled spontaneous growth, and their continued invasion and proliferation are considered to be primary causes of metastasis (45). In the present study, catalpol treatment inhibited the proliferation, invasion and migration of $\mathrm{HCC}$ cells, indicating that catalpol exhibited an anticancer effect on HCC cells. This finding was consistent with previous studies, which have reported that catalpol inhibits proliferation of bladder cancer cells by inducing apoptosis via blocking 
A

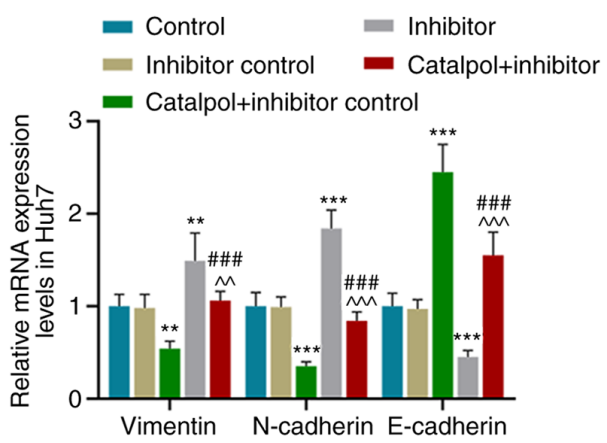

B
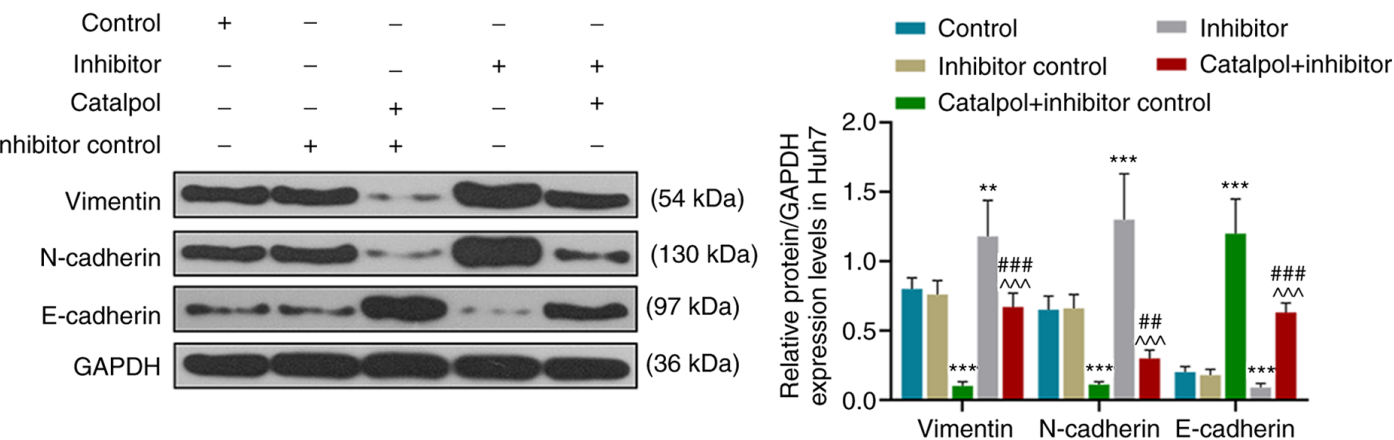

C
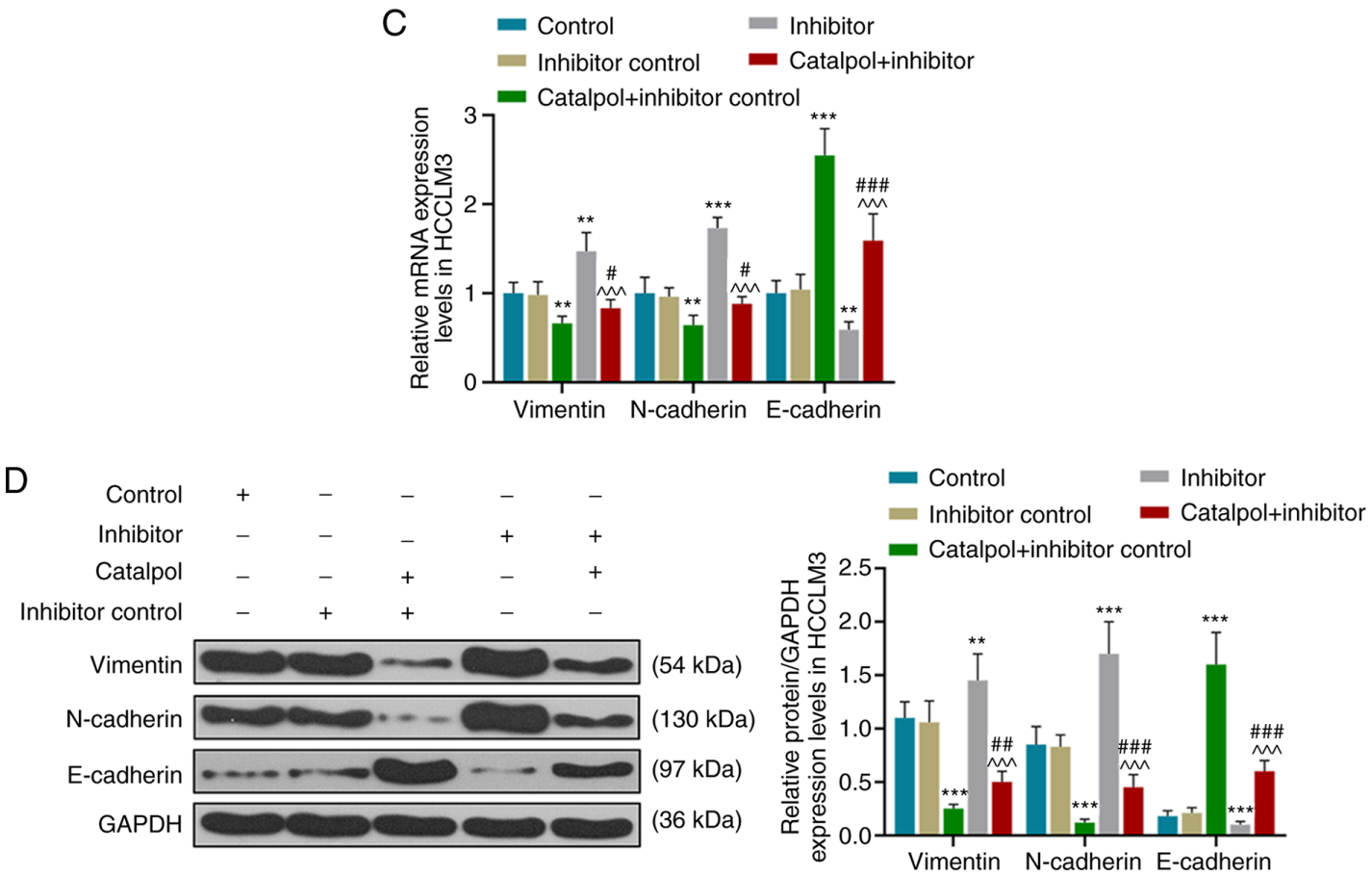

Figure 7. Catalpol inhibits epithelial-mesenchymal transformation of hepatocellular carcinoma cells via increasing the expression levels of miR-140-5p. (A) mRNA and (B) protein expression levels of vimentin, N-cadherin and E-cadherin in Huh7 cells were determined via RT-qPCR and western blotting. (C) mRNA and (D) protein expression levels of vimentin, N-cadherin and E-cadherin in HCCLM3 cells were determined via RT-qPCR and western blotting. ${ }^{* *} \mathrm{P}<0.01,{ }^{* * *} \mathrm{P}<0.001$ vs. Inhibitor control; ${ }^{\#} \mathrm{P}<0.05,{ }^{\# \#} \mathrm{P}<0.01,{ }^{\# \#} \mathrm{P}<0.001$ vs. Catalpol + Inhibitor control; ${ }^{\wedge} \mathrm{P}<0.01,{ }^{\wedge \wedge} \mathrm{P}<0.001$ vs. Inhibitor. RT-qPCR, reverse transcription-quantitative PCR.

AKT-mediated anti-apoptotic pathway signaling (46), and that catalpol inhibits the progression of colorectal cancer by inhibiting tumor angiogenesis and decreasing the inflammatory response (19).

EMT serves a key role in tumor invasion and metastasis $(47,48)$. The decrease and loss of E-cadherin expression is a significant hallmark in the occurrence of EMT in cancer cells, whereas the presence of vimentin and $\mathrm{N}$-cadherin expression levels are indicative of enhanced cell migration and invasion $(49,50)$. The present study demonstrated that catalpol treatment increased E-cadherin expression but decreased vimentin and $\mathrm{N}$-cadherin expression levels, and inhibited EMT of HCC cells, thus inhibiting tumor metastasis. Morphological observation further identified that catalpol treatment inhibited EMT in HCC. In the current study, TGF- $\beta 1$ was used to treat HCC cells; following treatment, cell morphology was altered, as indicated by the change in spindle shape, and cells lost their intercellular interactions. However, catalpol significantly 
decreased the morphological changes induced by TGF- $\beta 1$, indicating that catalpol exhibited a strong inhibitory effect on EMT. In line with these results, Wang et al (51) reported that catalpol inhibits cell proliferation via inhibiting EMT and promoting apoptosis of osteosarcoma cells.

A number of miRNAs, such as miR-139-5p (52), miR-21 (53), miR-487a (54) and miR-140-5p (27), have been reported to affect the proliferation and metastasis of HCC cells. In the present study, in vitro functional tests were performed and it was observed that decreasing miR-140-5p expression promoted cell migration, invasion and occurrence of EMT. These results were consistent with previous studies, which identified miR-140-5p as a tumor inhibitor (27,55). Zhao et al (56) revealed that catalpol inhibited cell proliferation, invasion and migration via regulating miR-22-3p/metastasis associated 1 family member 3 signaling in HCC. The present study also investigated the effects of catalpol on the expression levels of miR-140-5p and found that catalpol treatment significantly upregulated miR-140-5p expression. Therefore, it was hypothesized that catalpol may serve an anticancer role via mediating miR-140-5p expression. As miR-140-5p exhibits inhibitory effects on cancer progression, knockdown of miR-140-5p expression decreased the inhibitory effect of catalpol on HCC progression, indicating that the anticancer effect of catalpol on HCC cells may be achieved via increasing expression of miR-140-5p. However, there are certain limitations in the present study; for example, further investigation is required to determine whether miR-140-5p directly or indirectly reverses the anticancer effects of catalpol, and to identify the target gene for miR-140-5p. In addition, the results of the study require verification via in vivo experiments. Bioinformatic analysis of miR-140-5p targets followed by luciferase reporter assays to test the interaction between catalpol and miR-140 is also required.

In conclusion, the present study demonstrated that catalpol at different concentrations exhibited anticancer effects, which inhibited proliferation and migration of HCC cells, as well as the EMT. Moreover, the present results suggested that catalpol increased miR-140-5p expression, and that miR-140-5p knockdown decreased the antitumor ability of catalpol. Thus, the present study provides further understanding for novel approaches for the treatment of HCC.

\section{Acknowledgements}

Not applicable.

\section{Funding}

The present study was supported by the Science and Technology Development Project of Hangzhou (grant no. 20163501Y17).

\section{Availability of data and materials}

The datasets used and/or analyzed during the current study are available from the corresponding author on reasonable request.

\section{Authors' contributions}

LW and HL conceptualized and designed the study. SC, XW, $\mathrm{XC}$ and FW collected, analyzed and interpreted the data. LW and HL drafted and revised the manuscript. All authors agreed to be accountable for all aspects of the work in ensuring that questions related to the accuracy or integrity of the work are appropriately investigated and resolved. All authors read and approved the final manuscript.

\section{Ethics approval and consent to participate}

Not applicable.

\section{Patient consent for publication}

Not applicable.

\section{Competing interests}

The authors declare that they have no competing interests.

\section{References}

1. Intaraprasong P, Siramolpiwat S and Vilaichone RK: Advances in management of hepatocellular carcinoma. Asian Pac J Cancer Prev 17: 3697-3703, 2016.

2. Siegel RL, Miller KD and Jemal A: Cancer statistics, 2019. CA Cancer J Clin 69: 7-34, 2019.

3. Sakamoto M: Pathology of early hepatocellular carcinoma. Hepatol Res 37 (Suppl 2): S135-S138, 2007.

4. Wei PL, Huang CY and Chang YJ: Propyl gallate inhibits hepatocellular carcinoma cell growth through the induction of ROS and the activation of autophagy. PLoS One 14: e0210513, 2019.

5. Deng GL, Zeng S and Shen H: Chemotherapy and target therapy for hepatocellular carcinoma: New advances and challenges. World J Hepatol 7: 787-798, 2015.

6. Fang F, Yang L, Tao Y and Qin W: FBI-1 promotes cell proliferation and enhances resistance to chemotherapy of hepatocellular carcinoma in vitro and in vivo. Cancer 118: 134-146, 2012.

7. Moriguchi M, Umemura A and Itoh Y: Current status and future prospects of chemotherapy for advanced hepatocellular carcinoma. Clin J Gastroenterol 9: 184-190, 2016.

8. Clark T, Maximin S, Meier J, Pokharel S and Bhargava P: Hepatocellular carcinoma: Review of epidemiology, screening, imaging diagnosis, response assessment, and treatment. Curr Probl Diagn Radiol 44: 479-486, 2015.

9. $\mathrm{Xu} \mathrm{J}$ : Trends in liver cancer mortality among adults aged 25 and over in the United States, 2000-2016. NCHS Data Brief 1-8, 2018.

10. Liao CY, Lee CC, Tsai CC, Hsueh CW, Wang CC, Chen IH, Tsai MK, Liu MY, Hsieh AT, Su KJ, et al: Novel investigations of flavonoids as chemopreventive agents for hepatocellular carcinoma. Biomed Res Int 2015: 840542, 2015.

11. Liu C, Ma R, Wang L, Zhu R, Liu H, Guo Y, Zhao B, Zhao S, Tang J, Li Y, et al: Rehmanniae radix in osteoporosis: A review of traditional Chinese medicinal uses, phytochemistry, pharmacokinetics and pharmacology. J Ethnopharmacol 198: 351-362, 2017.

12. Kim SH, Yook TH and Kim JU: Rehmanniae radix, an effective treatment for patients with various inflammatory and metabolic diseases: Results from a review of Korean publications. J Pharmacopuncture 20: 81-88, 2017.

13. Lee B, Shim I, Lee H and Hahm DH: Rehmannia glutinosa ameliorates scopolamine-induced learning and memory impairment in rats. J Microbiol Biotechnol 21: 874-883, 2011.

14. Yuan CX, Chu T, Liu L, Li HW, Wang YJ, Guo AC and Fan YP: Catalpol induces oligodendrocyte precursor cell-mediated remyelination in vitro. Am J Transl Res 7: 2474-2481, 2015. 
15. Liu YR, Lei RY, Wang CE, Zhang BA, Lu H, Zhu HC and Zhang GB: Effects of catalpol on ATPase and amino acids in gerbils with cerebral ischemia/reperfusion injury. Neurol Sci 35: 1229-1233, 2014.

16. Li MY, Cheng XR, Zhou WX and Zhang YX: The effects of catalpol on Alzheimer's disease: Research advances. Journal of International Pharmaceutical Research 43: 199-204, 2016.

17. Zhu J, Chen X, Wang H and Yan Q: Catalpol protects mice against renal ischemia/reperfusion injury via suppressing PI3K/Akt-eNOS signaling and inflammation. Int J Clin Exp Med 8: 2038-2044, 2015

18. Zhang X, Zhang A, Jiang B, Bao Y, Wang J and An L: Further pharmacological evidence of the neuroprotective effect of catalpo from rehmannia glutinosa. Phytomedicine 15: 484-490, 2008.

19. Zhu P, Wu Y, Yang A, Fu X, Mao M and Liu Z: Catalpol suppressed proliferation, growth and invasion of CT26 colon cancer by inhibiting inflammation and tumor angiogenesis. Biomed Pharmacother 95: 68-76, 2017.

20. Liu C, Wu F, Liu Y and Meng C: Catalpol suppresses proliferation and facilitates apoptosis of MCF-7 breast cancer cells through upregulating microRNA-146a and downregulating matrix metalloproteinase-16 expression. Mol Med Rep 12: 7609-7614, 2015.

21. Wang ZH and Sheng HZ: Catalpol inhibits migration and induces apoptosis in gastric cancer cells and in athymic nude mice. Biomed Pharmacother 103: 1708-1719, 2018.

22. Adams BD, Kasinski AL and Slack FJ: Aberrant regulation and function of microRNAs in cancer. Curr Biol 24: R762-R776, 2014.

23. Seven M,Karatas OF, Duz MB and Ozen M: The role of miRNAs in cancer: From pathogenesis to therapeutic implications. Future Oncol 10: 1027-1048, 2014.

24. Fang Z, Yin S, Sun R, Zhang S, Fu M, Wu Y, Zhang T, Khaliq J and Li Y: miR-140-5p suppresses the proliferation, migration and invasion of gastric cancer by regulating YES1. Mol Cancer 16: 139, 2017.

25. Zhai H, Fesler A, Ba Y, Wu S and $\mathrm{Ju} \mathrm{J}$ : Inhibition of colorectal cancer stem cell survival and invasive potential by hsa-miR-140-5p mediated suppression of Smad2 and autophagy. Oncotarget 6: 19735-19746, 2015.

26. Lan H, Chen W, He G and Yang S: miR-140-5p inhibits ovarian cancer growth partially by repression of PDGFRA. Biomed Pharmacother 75: 117-122, 2015

27. Yan X, Zhu Z, Xu S, Yang LN, Liao XH, Zheng M, Yang D, Wang J, Chen D, Wang L, et al: MicroRNA-140-5p inhibits hepatocellular carcinoma by directly targeting the unique isomerase Pin1 to block multiple cancer-driving pathways. Sci Rep 7: 45915, 2017.

28. Li C, Zhou D, Hong H, Yang S, Zhang L, Li S, Hu P, Ren H, Mei Z and Tang H: TGF $\beta 1$-miR-140-5p axis mediated up-regulation of Flap endonuclease 1 promotes epithelial-mesenchymal transition in hepatocellular carcinoma. Aging (Albany NY) 11: 5593-5612, 2019.

29. Zou G, Zhong W, Wu F, Wang X and Liu L: Catalpol attenuates cardiomyocyte apoptosis in diabetic cardiomyopathy via Neat1/miR-140-5p/HDAC4 axis. Biochimie 165: 90-99, 2019.

30. Agarwal V, Bell GW, Nam JW and Bartel DP: Predicting effective microRNA target sites in mammalian mRNAs. ELife 4: e05005, 2015.

31. Rao X, Huang X, Zhou Z and Lin X: An improvement of the $2^{\wedge}$ (-delta delta CT) method for quantitative real-time polymerase chain reaction data analysis. Biostat Bioinforma Biomath 3: 71-85, 2013.

32. Mikaelian I, Malek M, Gadet R, Viallet J, Garcia A, Girard-Gagnepain A, Hesling C, Gillet G, Gonzalo P, Rimokh R and Billaud $\mathrm{M}$ : Genetic and pharmacologic inhibition of mTORC1 promotes EMT by a TGF- $\beta$-independent mechanism. Cancer Res 73: 6621-6631, 2013.

33. Gheldof A and Berx G: Cadherins and epithelial-to-mesenchymal transition. Prog Mol Biol Transl Sci 116: 317-336, 2013.

34. Yilmaz M and Christofori G: EMT, the cytoskeleton, and cancer cell invasion. Cancer Metastasis Rev 28: 15-33, 2009.

35. Villanueva A: Hepatocellular carcinoma. N Engl J Med 380: 1450-1462, 2019.

36. Jemal A, Ward EM, Johnson CJ, Cronin KA, Ma J, Ryerson B, Mariotto A, Lake AJ, Wilson R, Sherman RL, et al: Annual report to the nation on the status of cancer, 1975-2014, featuring survival. J Natl Cancer Inst 109: djx030, 2017.
37. Liang D, Xue H, Yu Y, Lv F, You W and Zhang B: Elevated expression of UHRF1 predicts unfavorable prognosis for patients with hepatocellular carcinoma. Int J Clin Exp Pathol 8: 9416-9421, 2015

38. Reig M, da Fonseca LG and Faivre S: New trials and results in systemic treatment of HCC. J Hepatol 69: 525-533, 2018.

39. Bai Y, Zhu R, Tian Y, Li R, Chen B, Zhang H, Xia B, Zhao D, Mo F, Zhang D and Gao S: Catalpol in diabetes and its complications: A review of pharmacology, pharmacokinetics, and safety. Molecules 24: 3302, 2019.

40. Lu J, Wang Y, Zhao W, Li N, Li H, Lu J, Zeng W, Bao S and Bai Y: Effects of catalpol, L-shikonin and paeonol extracted from radix rehmanniae, radix arnebiae and cortex moutan on KGF-induced HaCaT cell proliferation. Zhonghua Yi Xue Za Zhi 94: 1265-1269, 2014 (In Chinese).

41. Wang JH, Zou L, Wan D, Huifeng Z, Wang Y and Qin L: Review of catalpol's pleiotropic signaling pathways. Chin Pharmacol Bull 31: 1189-1194, 2015.

42. Wan D, Xue L, Zhu H and Luo Y: Catalpol induces neuroprotection and prevents memory dysfunction through the cholinergic system and BDNF. Evid Based Complement Alternat Med 2013: $134852,2013$.

43. Zhou J, Xu G, Ma S, Li F, Yuan M, Xu H and Huang K: Catalpol ameliorates high-fat diet-induced insulin resistance and adipose tissue inflammation by suppressing the JNK and NF- $\mathrm{B}$ pathways. Biochem Biophys Res Commun 467: 853-858, 2015

44. Cai Z, Xu K, Li Y, Lv Y, Bao J and Qiao L: Long noncoding RNA in liver cancer stem cells. Discov Med 24: 87-93, 2017.

45. Yang JY, Li D, Zhang Y, Guan BX, Gao P, Zhou XC and Zhou CJ The expression of MCM7 is a useful biomarker in the early diagnostic of gastric cancer. Pathol Oncol Res 24: 367-372, 2018.

46. Jin D, Cao M, Mu X, Yang G, Xue W, Huang Y and Chen H: Catalpol inhibited the proliferation of T24 human bladder cancer cells by inducing apoptosis through the blockade of Akt-mediated anti-apoptotic signaling. Cell Biochem Biophys 71: 1349-1356, 2015.

47. Brabletz T: EMT and MET in metastasis: Where are the cancer stem cells? Cancer Cell 22: 699-701, 2012.

48. Heerboth S, Housman G, Leary M, Longacre M, Byler S, Lapinska K, Willbanks A and Sarkar S: EMT and tumor metastasis. Clin Transl Med 4: 6, 2015.

49. De Craene B and Berx G: Regulatory networks defining EMT during cancer initiation and progression. Nat Rev Cancer 13: 97-110, 2013

50. Tiwari N, Gheldof A, Tatari M and Christofori G: EMT as the ultimate survival mechanism of cancer cells. Semin Cancer Biol 22: 194-207, 2012.

51. Wang L and Xue GB: Catalpol suppresses osteosarcoma cell proliferation through blocking epithelial-mesenchymal transition (EMT) and inducing apoptosis. Biochem Biophys Res Commun 495: 27-34, 2018.

52. Wu J, Zhang T, Chen Y and Ha S: MiR-139-5p influences hepatocellular carcinoma cell invasion and proliferation capacities via decreasing SLITRK4 expression. Biosci Rep 40: BSR20193295, 2020.

53. Wang $\mathrm{Y}$, Zhang $\mathrm{P}$, Yuan $\mathrm{M}$ and Li X: Overexpression of miRNA-21 promotes the proliferation and invasion in hepatocellular carcinoma cells via suppressing SMAD7. Technol Cancer Res Treat 18: 1533033819878686, 2019.

54. Kong Q, Liang C, Jin Y, Pan Y, Tong D, Kong Q and Zhou J: The lncRNA MIR4435-2HG is upregulated in hepatocellular carcinoma and promotes cancer cell proliferation by upregulating miRNA-487a. Cell Mol Biol Lett 24: 26, 2019.

55. Lv J, Fan HX, Zhao XP, Lv P, Fan JY, Zhang Y, Liu M and Tang H: Long non-coding RNA Unigene56159 promotes epithelial-mesenchymal transition by acting as a ceRNA of miR-140-5p in hepatocellular carcinoma cells. Cancer Lett 382: 166-175, 2016.

56. Zhao L, Wang Y and Liu Q: Catalpol inhibits cell proliferation, invasion and migration through regulating miR-22-3p/MTA3 signalling in hepatocellular carcinoma. Exp Mol Pathol 109: 51-60, 2019.

This work is licensed under a Creative Commons Attribution-NonCommercial-NoDerivatives 4.0 International (CC BY-NC-ND 4.0) License. 